\title{
The compositional and metabolic responses of gilthead seabream (Sparus aurata) to a gradient of dietary fish oil and associated $n-3$ long-chain PUFA content
}

\author{
Sam J. S. Houston ${ }^{1}$, Vasileios Karalazos ${ }^{2}$, John Tinsley $^{2}$, Mónica B. Betancor ${ }^{1}$, Samuel A. M. Martin ${ }^{3}$, \\ Douglas R. Tocher ${ }^{1}$ and Oscar Monroig ${ }^{1 *}$ \\ ${ }^{1}$ Institute of Aquaculture, Faculty of Natural Sciences, University of Stirling, Stirling FK9 4LA, Scotland, UK \\ ${ }^{2}$ BioMar Ltd, North Shore Road, Grangemouth Docks, Grangemouth FK3 8UL, Scotland, UK \\ ${ }^{3}$ Scottish Fish Immunology Research Centre, University of Aberdeen, Aberdeen AB24 2TZ, Scotland, UK \\ (Submitted 1 June 2017 - Final revision received 2 October 2017 - Accepted 5 October 2017 - First published online 20 November 2017)
}

\section{Abstract}

The replacement of fish oil (FO) with vegetable oil (VO) in feed formulations reduces the availability of $n$-3 long-chain PUFA (LC-PUFA) to marine fish such as gilthead seabream. The aim of this study was to examine compositional and physiological responses to a dietary gradient of $n$-3 LC-PUFA. Six iso-energetic and iso-nitrogenous diets (D1-D6) were fed to seabream, with the added oil being a blend of FO and VO to achieve a dietary gradient of $n$-3 LC-PUFA. Fish were sampled after 4 months feeding, to determine biochemical composition, tissue fatty acid concentrations and lipid metabolic gene expression. The results indicated a disturbance to lipid metabolism, with fat in the liver increased and fat deposits in the viscera reduced. Tissue fatty acid profiles were altered towards the fatty acid compositions of the diets. There was evidence of endogenous modification of dietary PUFA in the liver which correlated with the expression of fatty acid desaturase 2 (fads2). Expression of sterol regulatory element binding protein 1 (srebp1), fads 2 and fatty acid synthase increased in the liver, whereas PPAR $\alpha 1$ pathways appeared to be supressed by dietary VO in a concentration-dependent manner. The effects in lipogenic genes appear to become measurable in D1-D3, which agrees with the weight gain data suggesting that disturbances to energy metabolism and lipogenesis may be related to performance differences. These findings suggested that suppression of $\beta$-oxidation and stimulation of srebp1-mediated lipogenesis may play a role in contributing toward steatosis in fish fed $n$-3 LC-PUFA deficient diets.

\section{Key words: Gilthead seabream: Vegetable oils: Fish oils: Essential fatty acids: Lipid metabolism}

Sustainable expansion of aquaculture requires reduction in the use of fishmeal (FM) and fish oil (FO) in aquafeed formulations $^{(1-4)}$. Both raw materials, particularly FO, are rich in the two key $n$-3 long-chain ( $\geq \mathrm{C}_{20}$ ) PUFA (LC-PUFA), EPA (20:5n-3) and DHA (22:6n-3), recognised as essential fatty acids (EFA) for the majority of marine fish species ${ }^{(5)}$. DHA is an essential component of neural and retinal membranes ${ }^{(6)}$ and both EPA and DHA are precursors for an extensive range of autocrine signalling molecules (e.g. eicosanoids, resolvins, protectins, etc. ${ }^{(7)}$. Dietary deficiency of $n$-3 LC-PUFA has impacts on the health ${ }^{(8)}$, metabolism $^{(9,10)}$, composition ${ }^{(11,12)}$ and growth ${ }^{(13)}$ of marine fish.

Typically, an aquafeed for a given marine fish species contains a combination of FO to supply essential $n$ - 3 LC-PUFA and vegetable oils (VO) that, whereas devoid of LC-PUFA, supply dietary energy ${ }^{(14,15)}$. Marine fish lack sufficient activity of the LC-PUFA biosynthesis pathway to satisfy requirements ${ }^{(5)}$. In terms of fatty acid composition, the key effects of high inclusion levels of $\mathrm{VO}$ are an increase in $\mathrm{C}_{18}$ unsaturated fatty acids ( $\alpha$ linolenic acid, linoleic acid and oleic acid) in the fish tissues at the expense of LC-PUFA that is reflective of the altered composition of dietary fatty acids ${ }^{(16)}$. With regards to lipid metabolism, studies have reported that inclusion of dietary VO leads to reduced fatty acid catabolism and the accumulation of lipid in liver of Atlantic salmon (Salmo salar) and gilthead seabream, ${ }^{(17-19)}$. Studies examining the influence of VO on lipid biosynthesis have yielded conflicting results with some reporting increased gene expression in Atlantic salmon and black seabream (Acanthopagrus schlegelii) ${ }^{(18,19)}$ and others reporting decreased enzyme activity in gilthead seabream ${ }^{(20)}$ although, in mammals, EPA has been shown to supress lipogenesis ${ }^{(21)}$.

Lipid homoeostasis is maintained in animals through a balance of catabolic and anabolic processes. Fatty acids and cholesterol can be synthesised de novo by pathways that are activated by sterol regulatory element-binding proteins (Srebp)

Abbreviations: cDNA, complementary DNA; cpt1 $\alpha$, carnitine palmitoyl transferase I; EFA, essential fatty acids; fas, fatty acid synthase; fads2, fatty acid desaturase 2; FO, fish oil; LC-PUFA, long-chain PUFA; PCA, principal component analysis; srebp, sterol regulatory element-binding protein; qPCR, quantitative real time PCR; VO, vegetable oil.

* Corresponding author: O. Monroig, email oscar.monroig@stir.ac.uk 
1 and 2, respectively. Srebp are transcription factors involved in energy homoeostasis and have many target genes with examples of those in lipid metabolism including fatty acid synthase (fas) and fatty acid desaturase 2 ( $f a d s 2)$, the latter being key enzymes in the LC-PUFA biosynthesis pathway ${ }^{(22,23)}$. Fatty acids are catabolised by the $\beta$-oxidation pathway in either mitochondria or peroxisomes, and expression of genes encoding proteins involved in these pathways are regulated by, among others, Ppar ${ }^{(24)}$. Upon binding ligands and retinoid $\mathrm{X}$ receptor, $\mathrm{Ppars}$ bind to peroxisome proliferator response elements in the promoter regions of target genes, many of which are involved in $\beta$-oxidation, such as carnitine palmitoyl transferase I (cpt1 $\alpha)$ and liver-type fatty acid binding protein ( $f a b p 1$ ), both proteins involved in the intracellular transport of fatty acids destined for catabolism ${ }^{(24,25)}$

Despite recent advances in our knowledge regarding the impacts of dietary VO some questions remain, for instance, are dietary differences in gene expression dependent on precise concentrations of dietary nutrients or are genes activated/deactivated at particular levels of FO substitution? Therefore, the present study aimed to examine the impact of modern (high lipid, low FM) aquafeed formulations across a gradient of $n$-3 LC-PUFA, achieved by blending commercially available oils (FO, rapeseed oil and palm oil), on the biochemical composition of body compartments, and fatty acid compositions and gene expression in the liver and mid-intestine of a marine teleost, the gilthead seabream (Sparus aurata). The liver being a key metabolic tissue in vertebrate metabolism and the mid-intestine being a primary site of nutrient absorption and processing.

\section{Methods}

\section{Fish husbandry and diets}

The nutritional trial was carried out at the BioMar Feed Trial Unit between April and August 2014. Seabream juveniles of approximately $3 \mathrm{~g}$ were purchased from a commercial hatchery (Les Poissons du Soleil) and randomly distributed among $18 \times 1 \mathrm{~m}^{3}$ tanks. The tanks were part of a Recirculation Aquaculture System with photoperiod, temperature and salinity maintained at $12 \mathrm{~h}$ light $-12 \mathrm{~h}$ dark, $24^{\circ} \mathrm{C}$ and 32 parts per million, respectively. Initially, the fish were fed with commercial fry feeds rich in FM and FO until they reached approximately $24 \mathrm{~g}$. After acclimation, each tank was assigned one of six iso-energetic and iso-nitrogenous diets for 18 weeks, initially as a $3-\mathrm{mm}$ pellet ( 8 weeks) and then with a $4.5-\mathrm{mm}$ pellet to the end of the trial. Fish were fed to satiation twice per day using automatic feeders and waste feed was collected to accurately measure feed consumption. The six diets were formulated to deliver specific levels of LC-PUFA by progressively replacing FO with blends of rapeseed and palm oil, whereas the other dietary ingredients were selected to meet the known nutrient requirements of seabream ${ }^{(26)}$ (Table 1). Diets were produced by extrusion at the BioMar Tech-Centre. The experimental diets were numbered to reflect the VO/FO inclusion so that diet D1 contained the VO blend as sole exogenously added oil source, diet D6 contained only FO, and diets D2-D5 contained graded levels of $\mathrm{VO}$ and $\mathrm{FO}$ as described in Table 1 . The fatty acids that increased with dietary FO were: $16: 1 n-7,24: 1 n-9,20: 3 n-6$,
$20: 4 n-6,20: 4 n-3,20: 5 n-3,22: 5 n-3$ and $22: 6 n-3$, whereas $20: 0,22: 0,18: 1 n-9,18: 2 n-6$ and $18: 3 n-3$ increased with dietary VO (Table 2).

Table 1. Diet formulations and proximate analyses of the six experimental diets

\begin{tabular}{|c|c|c|c|c|c|c|}
\hline & \multicolumn{6}{|c|}{ Diet } \\
\hline & D1 & D2 & D3 & D4 & D5 & D6 \\
\hline \multicolumn{7}{|l|}{ Ingredients (\%) } \\
\hline Fishmeal & $12 \cdot 5$ & 12.5 & 12.5 & $12 \cdot 5$ & 12.5 & 12.5 \\
\hline Soya protein concentrate & 21.9 & 21.9 & 21.9 & 21.9 & 21.9 & 21.9 \\
\hline Rapeseed meal & $10 \cdot 0$ & $10 \cdot 0$ & $10 \cdot 0$ & $10 \cdot 0$ & $10 \cdot 0$ & $10 \cdot 0$ \\
\hline Wheat gluten & 4.0 & 4.0 & 4.0 & 4.0 & 4.0 & 4.0 \\
\hline Maize gluten & $25 \cdot 0$ & $25 \cdot 0$ & $25 \cdot 0$ & $25 \cdot 0$ & $25 \cdot 0$ & $25 \cdot 0$ \\
\hline Wheat & $7 \cdot 1$ & $7 \cdot 1$ & $7 \cdot 1$ & $7 \cdot 1$ & $7 \cdot 1$ & $7 \cdot 1$ \\
\hline Amino acids ${ }^{\star}$ & 0.8 & 0.8 & 0.8 & 0.8 & 0.8 & 0.8 \\
\hline Micro-ingredients $\dagger$ & $3 \cdot 1$ & $3 \cdot 2$ & 3.2 & $3 \cdot 3$ & 3.5 & 3.9 \\
\hline Yttrium & 0.03 & 0.03 & 0.03 & 0.03 & 0.03 & 0.03 \\
\hline \multicolumn{7}{|l|}{ Oils (\%) } \\
\hline Fish oil (SA) & 0.0 & 1.8 & $2 \cdot 6$ & 4.4 & $8 \cdot 0$ & 14.9 \\
\hline Rapeseed oil & $10 \cdot 4$ & $9 \cdot 2$ & $8 \cdot 6$ & $7 \cdot 3$ & 4.8 & 0.0 \\
\hline Palm oil & $5 \cdot 2$ & 4.6 & $4 \cdot 2$ & 3.6 & $2 \cdot 4$ & 0.0 \\
\hline \multicolumn{7}{|c|}{ Proximate composition (\% of diet as fed) } \\
\hline Protein & 41.8 & 43.0 & $42 \cdot 9$ & $41 \cdot 7$ & $42 \cdot 4$ & $42 \cdot 5$ \\
\hline Lipid & $22 \cdot 2$ & $21 \cdot 7$ & $21 \cdot 7$ & 21.5 & $21 \cdot 8$ & $20 \cdot 8$ \\
\hline Ash & $6 \cdot 1$ & $6 \cdot 1$ & 5.9 & 5.9 & $6 \cdot 1$ & $6 \cdot 2$ \\
\hline Moisture & $10 \cdot 3$ & $9 \cdot 7$ & 9.4 & $10 \cdot 7$ & 8.9 & 8.9 \\
\hline Crude energy (MJ/kg)‡ & $22 \cdot 0$ & $22 \cdot 1$ & $22 \cdot 2$ & $21 \cdot 8$ & $22 \cdot 2$ & $22 \cdot 0$ \\
\hline
\end{tabular}

* Lysine and methionine.

† Vitamin and mineral premix, monocalcium-phosphate, cholesterol, Emulthin G35, antioxidants

‡ Estimated by using the mean values of gross energy for proteins, lipids and carbohydrates $23 \cdot 6,39.5$ and $17.2 \mathrm{~kJ} / \mathrm{g}$, respectively ${ }^{(15)}$

Table 2. Fatty acid composition of the experimental diets (D1-D6) given as percentage of total fatty acids*

\begin{tabular}{|c|c|c|c|c|c|c|}
\hline Fatty acids (\%) & D1 & $\mathrm{D} 2$ & D3 & D4 & D5 & D6 \\
\hline Lipid (\%) & $22 \cdot 16$ & $21 \cdot 71$ & $21 \cdot 71$ & 21.47 & $21 \cdot 82$ & $20 \cdot 82$ \\
\hline $14: 0$ & 0.55 & 1.07 & 1.47 & $2 \cdot 10$ & 3.34 & $5 \cdot 73$ \\
\hline $16: 0$ & $15 \cdot 44$ & $15 \cdot 62$ & $15 \cdot 71$ & $16 \cdot 05$ & $16 \cdot 69$ & $17 \cdot 52$ \\
\hline $18: 0$ & 2.53 & 2.62 & $2 \cdot 67$ & $2 \cdot 80$ & 3.04 & 3.43 \\
\hline $20: 0$ & 0.46 & 0.38 & 0.43 & 0.41 & 0.36 & 0.26 \\
\hline $22: 0$ & 0.23 & 0.23 & 0.22 & 0.21 & 0.19 & 0.16 \\
\hline$\Sigma$ SFA & $19 \cdot 35$ & 20.04 & $20 \cdot 64$ & $21 \cdot 70$ & 23.75 & $27 \cdot 22$ \\
\hline $16: 1 n-7$ & 0.51 & 1.12 & 1.48 & $2 \cdot 20$ & 3.65 & $6 \cdot 71$ \\
\hline $18: 1 n-9$ & $47 \cdot 13$ & 43.91 & 41.89 & 37.57 & 29.37 & $12 \cdot 38$ \\
\hline $18: 1 n-7$ & 2.47 & 2.55 & 2.58 & 2.69 & 2.77 & 2.99 \\
\hline $20: 1 n$ & 0.93 & 0.97 & 0.98 & 1.04 & $1 \cdot 11$ & 1.29 \\
\hline $22: 1 n-11$ & 0.08 & 0.14 & 0.19 & 0.28 & 0.43 & 0.75 \\
\hline $24: 1 n-9$ & 0.14 & 0.17 & 0.19 & 0.23 & 0.29 & 0.47 \\
\hline$\Sigma$ MUFA & $51 \cdot 32$ & 48.92 & $47 \cdot 37$ & $44 \cdot 10$ & $37 \cdot 77$ & 24.69 \\
\hline $18: 2 n-6$ & 21.42 & $20 \cdot 42$ & 19.69 & 18.56 & $16 \cdot 16$ & $11 \cdot 22$ \\
\hline $18: 3 n-6$ & 0.00 & 0.03 & 0.04 & 0.07 & 0.12 & 0.25 \\
\hline $20: 2 n-6$ & 0.06 & 0.07 & 0.07 & 0.08 & 0.10 & 0.14 \\
\hline $20: 4 n-6$ & 0.05 & 0.11 & 0.15 & 0.23 & 0.40 & 0.78 \\
\hline $22: 5 n-6$ & 0.00 & 0.04 & 0.05 & 0.09 & 0.16 & 0.31 \\
\hline$\Sigma n-6$ PUFA & 21.52 & 20.67 & $20 \cdot 01$ & $19 \cdot 03$ & 17.01 & 12.90 \\
\hline $18: 3 n-3$ & 6.05 & 5.69 & $5 \cdot 52$ & 5.03 & 3.99 & 1.76 \\
\hline $18: 4 n-3$ & 0.08 & 0.30 & 0.44 & 0.70 & $1 \cdot 23$ & 2.40 \\
\hline $20: 4 n-3$ & 0.03 & 0.08 & 0.11 & 0.18 & 0.32 & 0.62 \\
\hline $20: 5 n-3$ & 0.70 & 1.96 & $2 \cdot 73$ & $4 \cdot 32$ & $7 \cdot 48$ & $14 \cdot 34$ \\
\hline $22: 5 n-3$ & 0.11 & 0.26 & 0.35 & 0.53 & 0.91 & 1.71 \\
\hline $22: 6 n-3$ & 0.63 & 1.47 & 1.98 & 3.06 & $5 \cdot 23$ & 9.89 \\
\hline$\Sigma n-3$ PUFA & $7 \cdot 61$ & $9 \cdot 76$ & $11 \cdot 13$ & 13.83 & $19 \cdot 16$ & 30.77 \\
\hline
\end{tabular}

* Trace $(<0.05)$ fatty acids have been removed. 
Experimental animals were maintained under the current European legislation on handling experimental animals. In addition, all research performed by the Institute of Aquaculture, University of Stirling (UoS) is subject to thorough ethical review carried out by the UoS Animal Welfare and Ethical Review Board (AWERB) before any work being approved. This involves all projects, irrespective of where they are carried out, to be submitted to AWERB for approval using detailed Ethical Approval forms that require all aspects of the experimentation to be described including all animal health and welfare issues as well as other ethical considerations. The present research was assessed by the UOS AWERB and passed the ethical review process of the University of Stirling.

\section{Sampling}

Fish were sampled at the initiation of the trial and at termination after being euthanised with a lethal dose of benzocaine (Centrovet, Kalagin). Fish were not fed the day before sampling. Five whole fish and three eviscerated carcasses, liver and viscera (the entire contents of the body cavity minus the liver) were sampled from each tank for compositional analysis. Three fish per tank were also sampled for gene expression and fatty acid composition taking samples of liver and mid-intestine. Samples for RNA analysis were incubated with $1 \mathrm{ml}$ RNAlater ${ }^{\circledR}$ at $4^{\circ} \mathrm{C}$ for $24 \mathrm{~h}$ (Sigma-Aldrich) before storage at $-70^{\circ} \mathrm{C}$, whereas samples for fatty acid analysis were immediately frozen and stored at $-20^{\circ} \mathrm{C}$ before shipment on dry ice to the Institute of Aquaculture, University of Stirling.

\section{Proximate composition}

Feed samples were ground before analyses. Whole fish, carcass and viscera samples were homogenised in a blender (Waring Laboratory Science) to produce pates. Proximate compositions of feeds and fish were determined according to standard procedures $^{(27)}$. Moisture contents were obtained after drying in an oven at $110^{\circ} \mathrm{C}$ for $24 \mathrm{~h}$ and ash content determined after incineration at $600^{\circ} \mathrm{C}$ for $16 \mathrm{~h}$. Crude protein content was measured by determining nitrogen content $(\mathrm{N} \times 6 \cdot 25)$ using automated Kjeldahl analysis (Tecator Kjeltec Auto 1030 analyser; Foss) and total lipid content determined as described below.

\section{Lipid extraction}

Total lipid for fatty acid analyses was extracted from seabream tissues according to Folch et al. ${ }^{(28)}$. In brief, liver and midintestine samples (approximately $0.5 \mathrm{~g}$ ) were homogenised in $20 \mathrm{ml}$ chloroform-methanol $(2: 1, \mathrm{v} / \mathrm{v})$ and incubated for $1 \mathrm{~h}$ on ice. Subsequently, $5 \mathrm{ml}$ of $0.88 \% \mathrm{KCl}(\mathrm{w} / \mathrm{v})$ was added, samples were vortexed and centrifuged at $400 \boldsymbol{g}$ to separate organic and aqueous fractions. The aqueous fraction was discarded and the organic layer (infranatant) was then filtered (Whatman No. 1) and solvent evaporated under a stream of $\mathrm{O}_{2}$-free $\mathrm{N}_{2}$. After desiccation in vaccuo overnight, lipid content was determined gravimetrically. Total lipid samples were stored at $10 \mathrm{mg} / \mathrm{ml}$ in chloroform-methanol $(2: 1, \mathrm{v} / \mathrm{v})$ containing $0.01 \%(\mathrm{w} / \mathrm{v})$ butylated hydroxytoluene as antioxidant.

\section{Fatty acid analysis}

Fatty acids were quantified by GLC after preparation of fatty acid methyl esters (FAME) by acid-catalysed transesterification of total lipid $^{(29)}$. In brief, $1 \mathrm{mg}$ of total lipid and $0.1 \mathrm{mg}$ of heptadecanoic acid $(17: 0)$ as internal standard were incubated with $1 \mathrm{ml}$ toluene and $2 \mathrm{ml} 1 \%$ sulphuric acid in methanol (v/v) for $16 \mathrm{~h}$ at $50^{\circ} \mathrm{C}$. FAME were extracted and purified by TLC as described by Tocher \& Harvie ${ }^{(30)}$ and resuspended in isohexane before GC analysis using a Fisons GC-8160 (Thermo Scientific) equipped with a $30 \mathrm{~m} \times 0.32 \mathrm{~mm}$ internal diameter $\times 0.25 \mu \mathrm{m} \quad$ ZB-wax column (Phenomenex), on-column injector and a flame ionisation detector. Data were collected and processed using Chromcard for Windows (version 2.01; Thermoquest Italia S.p.A.). FAME were identified by comparison to known standards (Supelco 37-FAME mix; Sigma-Aldrich Ltd) and published data ${ }^{(30)}$. Fatty acid contents were expressed as $\mathrm{mg} / \mathrm{g}$ of tissue and estimated using the response of the internal standard. The $\mathrm{CV}$ estimated using mg $\mathrm{DHA} / \mathrm{g}$ over a subset of twenty samples was $2 \cdot 80$ (sD $2 \cdot 51$ )\%.

\section{RNA extraction}

Total RNA was extracted from approximately $100 \mathrm{mg}$ of liver and mid-intestine by homogenisation in $1 \mathrm{ml}$ of TriReagent (SigmaAldrich) using a Mini-Beadbeater 24 (Biospec). Phase separation was achieved by the addition of $100 \mu \mathrm{l}$ of 1-bromo-3-chloropropane (Sigma) and centrifugation at $20000 \mathrm{~g}$. Subsequently $400 \mu \mathrm{l}$ of the supernatant were recovered and RNA precipitated by the addition of $200 \mu \mathrm{l}$ isopropanol (Fisher) and $200 \mu \mathrm{l}$ RNA precipitation solution ( $1.2 \mathrm{~m}$ sodium chloride and $0.8 \mathrm{~m}$ sodium citrate sesquihydrate) followed by centrifugation at $20000 \mathrm{~g}$. The resulting pellet was washed twice with $75 \%$ ethanol, air-dried and resuspended in $50 \mu \mathrm{l}$ nuclease-free water. The concentration and quality were verified spectrophotometrically (NanoDrop ND-1000 Spectrophotometer; Thermo Scientific) and by agarose gel electrophoresis to visualise the presence of $18 \mathrm{~S}$ and $28 \mathrm{~S}$ ribosomal subunits. Extracts were stored at $-70^{\circ} \mathrm{C}$ until complementary DNA (cDNA) synthesis.

\section{Complementary DNA synthesis}

Reverse transcription was performed according to the kit manufacturer's protocol (High Capacity Reverse Transcription kit; Applied Biosystems). A no template control reaction and RT-free reactions were prepared as blank and negative controls. Each $20 \mu \mathrm{l}$ reaction included: $10 \times$ reverse transcription buffer $(2 \mu \mathrm{l}), 100 \mathrm{~mm}$ deoxyribonucleotide triphosphate (dNTP) mix $(0 \cdot 8 \mu \mathrm{l}), 10 \mu \mathrm{M}$ random primers $(1 \cdot 5 \mu \mathrm{l}), 10 \mu \mathrm{M}$ oligo dT primers $(0.5 \mu \mathrm{l})$, RT $(1.0 \mu \mathrm{l}), 2 \mu \mathrm{g}$ of total RNA as template and nucleasefree water to make up the volume. RNA was denatured at $95^{\circ} \mathrm{C}$ for $10 \mathrm{~min}$ before addition of master mix containing all other reagents. Reverse transcription was performed on a Biometra Thermocycler (Analytik Jena) using the following programme: $25^{\circ} \mathrm{C}$ for $10 \mathrm{~min}, 37^{\circ} \mathrm{C}$ for $120 \mathrm{~min}, 85^{\circ} \mathrm{C}$ for $5 \mathrm{~min}$ and then terminated at $4^{\circ} \mathrm{C}$. A pool of cDNA samples was created for serial dilutions, calibrator samples and primer validations. Samples of cDNA were diluted 20-fold with nuclease-free water as template for quantitative real time PCR (qPCR), and stored at $-20^{\circ} \mathrm{C}$. 


\section{Gene expression analysis}

Gene expression was determined for candidate genes involved in key pathways by qPCR. Primers for qPCR were designed using Primer3 through the NCBI database's 'Primer-BLAST' against known gene sequences including sequences from the $S$. aurata expressed sequence tag NCBI database that were confirmed to be the gene of interest by BLAST searches. Primer sequences for genes in the present study are given in Table 3. Primers were tested to confirm that they functioned optimally at annealing temperatures of $60^{\circ} \mathrm{C}$ and that a single amplicon of appropriate length was visualised on agarose gel. A serial dilution of the cDNA pool was analysed by qPCR (Luminaris Color HiGreen qPCR Master Mix; Thermo Scientific) to determine primer efficiency (rejected at $<1.85$ ). Duplicated qPCR reactions were carried out on 96-well plates, each reaction contained: Luminaris Color HiGreen $(10 \mu \mathrm{l}), 10 \mu \mathrm{M}$ primers $(1 \mu \mathrm{l}$ each), 1/20 diluted cDNA sample ( 5 and $2 \mu$ for target and reference genes, respectively) and nuclease-free water up to $20 \mu \mathrm{l}$. As there were fifty-four samples per tissue (six treatments, $n$ 9) two plates were run per gene with treatments equally represented on both plates, a 1/20 dilution of the cDNA pool was used as a calibrator and a serial dilution included on one plate. A single master mix was used for all the reactions required per gene and both plates were run consecutively on a Biometra TOptical Thermocycler (Analytik Jena). The thermocycling programme was $50^{\circ} \mathrm{C}$ for $2 \mathrm{~min}, 95^{\circ} \mathrm{C}$ for $10 \mathrm{~min}$, thirty-five cycles of $95^{\circ} \mathrm{C}$ for $15 \mathrm{~s}$ (denaturation), $60^{\circ} \mathrm{C}$ for $30 \mathrm{~s}$ (annealing) and $72^{\circ} \mathrm{C}$ (extension) for $30 \mathrm{~s}$, followed by a melting curve to check for non-specific products. Data were acquired through the software package qPCRsoft 3.1 (Analytik Jena) and calculations for sample expression ratios were carried out according to Pfaffl $^{(31)}$ :

$$
\text { Expression ratio }=\frac{E(\text { ref })^{C_{t}(\text { Sample })}}{E(\text { goi })^{C_{t}(\text { Sample })}} \div \frac{E(\text { ref })^{C_{t}(\text { Calibrator })}}{E(\text { goi })^{C_{t}(\text { Calibrator })}}
$$

where $E$ is the determined efficiency; ref the geometric mean of four reference genes, goi the gene of interest and $C_{t}$ the threshold cycle. The genes of interest were normalised to the geometric mean of four reference genes, elongation factor $1 \alpha(e f 1 \alpha), \beta$-actin, $\alpha$-tubulin and ribosomal protein P0, whose expression was not influenced by dietary treatment. Gene expression data are presented as $\log 2$ expression ratios $^{(32)}$ of genes related to lipid metabolism: srebp1, srebp2, ppara 1, fas, fads2, cpt1 $\alpha$ and fabp1 and elongation of very long-chain fatty acid 5 protein (elovl5). The average intra assay CV was $0.44(\mathrm{SD} 0 \cdot 12) \%$ at the level of quantification cycle $\left(C_{q}\right)$.

\section{Statistical analysis}

Final weights, specific growth rate (SGR), proximate composition and tissue fatty acids were analysed by between groups ANOVA, rejecting null hypotheses at $P<0.05$. Absence of within treatment effects (i.e. tank effects) were first confirmed using tank as a nested variable in the ANOVA formula. F-tests were verified by Bartlett's test and Shapiro-Wilk for variance homogeneity and distribution.

Table 3. Primer sequences used for gene expression analysis by quantitative RT PCR.Amplicon sizes (bp) and GenBank accession numbers also are provided

\begin{tabular}{|c|c|c|c|}
\hline Transcripts & Sequence $\left(5^{\prime}-3^{\prime}\right)$ & Amplicon (bp) & Accession no \\
\hline \multirow[t]{2}{*}{ fads2 } & Forward: GCAGGCGGAGAGCGACGGTCTGTTCC & 72 & AY055749 \\
\hline & Reverse: AGCAGGATGTGACCCAGGTGGAGGCAGAAG & & \\
\hline \multirow[t]{2}{*}{ elovl5 } & Forward: CСTCCTGGTGCTCTACAAT & 112 & AY660879 \\
\hline & Reverse: GTGAGTGTCCTGGCAGTA & & \\
\hline \multirow[t]{2}{*}{ cpt1a } & Forward: GTGCCTTCGTTCGTTCCATGATC & 82 & JQ308822 \\
\hline & Reverse: TGATGCTTATCTGCTGCCTGTTTG & & \\
\hline srebp1 & Forward: AGGGCTGACCACAACGTCTCCTCTCC & 77 & JQ277709 \\
\hline \multirow[t]{2}{*}{ ppara 1} & Forward: TCTCTTCAGCCCACCATCCC & 116 & AY590299 \\
\hline & Reverse: ATCCCAGCGTGTCGTCTCC & & \\
\hline \multirow[t]{2}{*}{ fabp1 } & Forward: CATGAAGGCGATTGGTCTCC & 165 & KF857311 \\
\hline & Reverse: GTCTCCAAGTCTGCСТCCTT & & \\
\hline \multirow[t]{2}{*}{ srebp2 } & Forward: GCTCACAAGCAAAATGGCCT & 240 & AM970922.1 \\
\hline & Reverse: CAАAАСТGСТСССТТССССА & & \\
\hline \multirow[t]{2}{*}{ fas } & Forward: TGCCATTGCCATAGCACTCA & 172 & JQ277708.1 \\
\hline & Reverse: ACCTTTGCCCTTTGTGTGGA & & \\
\hline \multirow{2}{*}{$\beta$-act } & Forward: TCCTGCGGAATCCATGAGA & 50 & X89920 \\
\hline & Reverse: GACGTCGCACTTCATGATGCT & & \\
\hline \multirow[t]{2}{*}{ ef1a } & Forward: ACGTGTCCGTCAAGGAAATC & 109 & AF184170 \\
\hline & Reverse: GGGTGGTTCAGGATGATGAC & & \\
\hline \multirow[t]{2}{*}{ tuba1a } & Forward: ATCACCAATGCCTGCTTCGA & 214 & AY326430.1 \\
\hline & Reverse: CTGTGGGAGGCTGGTAGTTG & & \\
\hline \multirow[t]{2}{*}{ rplpo } & Forward: GAACACTGGTCTGGGTCCTG & 159 & AY550965.1 \\
\hline & Reverse: TTCAGCATGTTGAGGAGCGT & & \\
\hline
\end{tabular}

fads2, fatty acid desaturase 2; elov/5, elongation of very long-chain fatty acid 5 protein; cpt1a, carnitine palmitoyl transferase I; srebp1, sterol regulatory element-binding protein 1; fabp1, fatty acid binding protein; srebp2, sterol regulatory element-binding protein 2 ; fas, fatty acid synthase; $\beta$-act, $\beta$ actin; ef1a, elongation factor $1 a$; tuba1, a-tubulin; rplp0, ribosomal protein P0. 
Three individuals from each tank (nine per treatment) were randomly sampled giving fifty-four fish in total, this is the minimum number of fish to detect medium effect sizes $\left(f^{2}=0.15\right.$; power $\left.=0.8\right)$ by ordinary least squares regression. Proximate composition data were analysed using linear regression to identify the existence of trends across the experimental diets. Trends were reported as significant if the slope was significantly different $(P<0.05)$ to 0 . For fatty acid profiles of tissues ( $n$ 54) the first step of analysis was to reduce the dimensions of the data by principal component analysis (PCA), which enabled the identification of fatty acids that were correlated with each other and that should be analysed further. The level of dietary FO was supplied as a supplementary variable to PCA. Fatty acids with several no detects (effectively zero) were removed from the data set, because zero values are problematic with PCA analysis, and the $\mathrm{C}_{20}$ and $\mathrm{C}_{22}$ MUFA were combined into two single variables (20:1 and $22: 1$, respectively) as these peaks do not always separate in the GC analysis. Further analyses of selected fatty acids were performed using regression of the tissue fatty acid concentration as a function of the diet fatty acid concentration. Tissue fatty acid levels were regressed with absolute data $(\mathrm{mg} / \mathrm{g}$ tissue). Where a range was reported, this was derived from the fitted values of the model applied to the data, not the mean values reported in the online Supplementary Tables. Where appropriate, percentage data (\% of total fatty acids) were used to support the analyses. When a fatty acid did not have a dietary component it was regressed against dietary VO, for instance the fatty acid 18:2n-9, and the expression of genes. Analyses and plots were produced in the statistical package $\mathrm{R}^{(33)}$ (version 3.1.3). PCA were performed using the FactoMineR package ${ }^{(34)}$ and regression diagnostics using the Car package ${ }^{(35)}$

\section{Results}

\section{Growth rates and proximate composition of} gilthead seabream

After feeding the experiment diets for 18 weeks mean weights ranged between 200 and $250 \mathrm{~g}$ and SGR between 1.64 and 1.81 , with significant differences $(P<0.001)$ between dietary groups that showed increasing the dietary VO content beyond the level of that in diet D4 led to reduced growth (Table 4).

Significant effects of diet on proximate compositions of gilthead seabream were observed in liver, mid-intestine and viscera. In liver and mid-intestine, total lipid contents increased from 18.6 to $31.8 \% \operatorname{diet}\left(R^{2}=67.8, P<0.001\right)$ and 8.6 to $13.9 \%$ $\left(R^{2}=23.9, P<0.001\right)$, respectively, as dietary VO increased from 0 to $15.6 \%$ of diet. In viscera (minus liver), total lipid content decreased from 53.5 to $45.2 \%\left(R^{2}=24 \cdot 0, P<0.001\right)$ as dietary VO increased in the diet. The lipid contents of whole fish and carcass were unaffected by dietary treatment $(P>0.05)$. Protein and ash contents were not affected in any body compartment examined in the present study $(P>0.05)$. A summary of these data is presented in the online Supplementary Table S1.
Table 4. Final weights and specific growth rates of Sparus aurata after 18 weeks feeding on diets (D1-D6)

(Mean values and standard deviations)

\begin{tabular}{lllllr}
\hline & \multicolumn{2}{c}{ Weight $(\mathrm{g})$} & & \multicolumn{2}{c}{ SGR $^{*}$} \\
\cline { 2 - 3 } Diets & Mean & SD & & Mean & SD \\
\hline D1 & $198 \cdot 6^{\mathrm{c}}$ & 1.3 & $1.64^{\mathrm{d}}$ & 0.01 \\
D2 & $219.4^{\mathrm{b}}$ & 6.6 & & $1.72^{\mathrm{c}}$ & 0.02 \\
D3 & $224.8^{\mathrm{b}}$ & 5.0 & & $1.75^{\mathrm{c}, \mathrm{b}}$ & 0.01 \\
D4 & $241.3^{\mathrm{a}}$ & 3.1 & & $1.78^{\mathrm{a}, \mathrm{b}}$ & 0.00 \\
D5 & $245.0^{\mathrm{a}}$ & 4.0 & & $1.81^{\mathrm{a}}$ & 0.01 \\
D6 & $248.3^{\mathrm{a}}$ & 1.5 & & $1.81^{\mathrm{a}}$ & 0.01 \\
ANOVA & \multicolumn{2}{c}{$P<0.001$} & & \multicolumn{2}{c}{$P<0.001$} \\
\hline
\end{tabular}

a,b,c,d Mean values with unlike superscript letters were significantly different between group differences by ANOVA.

* $S G R=($ In final weight - In initial weight $) / d \times 100$.

\section{Fatty acid composition of liver and mid-intestine}

Fatty acid profiles of total lipid of two major lipid metabolic sites, namely liver and mid-intestine, were determined and further analysed by PCA. In both the liver and mid-intestine the first principal component (PC1) was correlated to dietary FO and explained 57.5 and $60.1 \%$ of the variance in fatty acid compositions, respectively (Fig. 1 and 2). The fatty acids associated with FO, namely $14: 0,16: 1 n-7,20: 4 n-3,20: 5 n-3$, $22: 5 n-3$ and $22: 6 n-3$, had positive correlations to PC1, and those associated with VO, specifically $18: 1 n-9,18: 2 n-6$ and $18: 3 n-3$, a negative correlation to PC1 in liver and mid-intestine Thus, PC1 separated the fatty acid profiles according to diet, D1 had low values and D6 had high values for PC1. PC2 accounted for 15.3 and $15.5 \%$ of the variance in liver and mid-intestine fatty acid profiles, respectively. The contributions of the fatty acids towards PC2, which separated the profiles vertically in Fig. 1 and 2, differed between liver and mid-intestine. In liver, $20: 2 n-6$ and $20: 1$ had a positive influence on PC2, and 18: $2 n-9,20: 2 n-9,18: 3 n-6,20: 3 n-6$ a negative influence, with these fatty acids thus being important to separate individual fatty acid profiles once the variability due to PC1 (diet) had been accounted for. In the case of mid-intestine samples, 18:0, $20: 0$ and $22: 0$ had a positive influence, and $18: 1 n-7$ a negative influence on PC2 while $18: 2 n-9$ and $20: 2 n-9$ were not detected, again it can be interpreted that these are the fatty acids that vary the most between individual fatty acid profiles once the effect of PC1 had been removed. It was also apparent from biplots that there was considerable overlap between the fatty acid profiles of liver and mid-intestine of fish consuming diets D1-D4, although fatty acid profiles from individuals fed on diets containing the highest inclusion levels of FO (D5 and D6) formed clearly separated groups (Fig. 1(a) and 2(a)). PCA indicated that the $n-3$ LC-PUFA (20:3n-3, $20: 4 n-3$, EPA, DPA and DHA) were all correlated with each other in both liver and mid-intestine and therefore these fatty acids were summed as a single variable reflecting their origin from FO. Absolute levels of tissue $n$ - 3 LC-PUFA were strongly related to dietary $n-3$ LCPUFA in liver $\left(R^{2}=0.75, P<0.001\right)$ and mid-intestine $\left(R^{2}=0.87\right.$, $P<0.001$ ) (Fig. 3). Absolute levels of MUFA responded positively to dietary MUFA in liver $\left(R^{2}=0.57, P<0.001\right)$ and midintestine $\left(R^{2}=0.76, P<0.001\right)$ (Fig. 4). Contents of MUFA in 
(a)

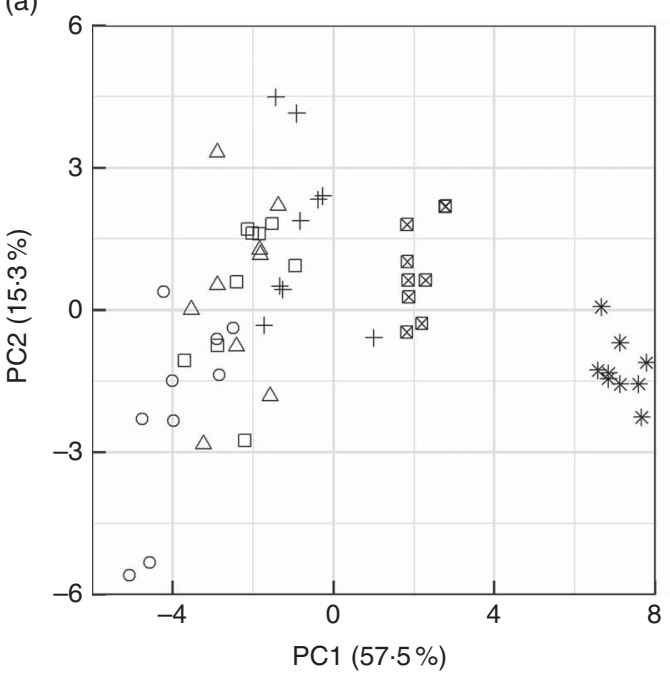

(b)

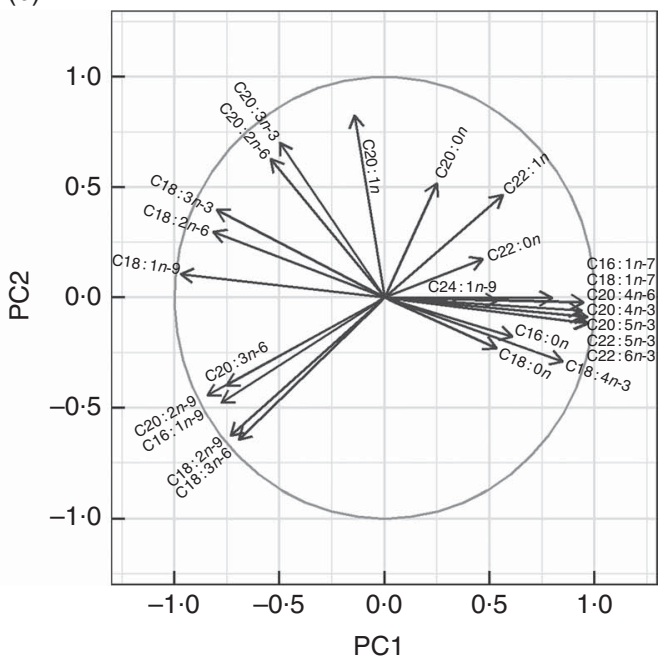

Fig. 1. Graphical representation of principal components analysis (PCA) of fatty acid profiles from liver ( $n 54)$ of fish fed experimental diets (D1-D6). The two panels are complimentary to one another. (a) Biplot of the first two principal components (PC1 and PC2) of gilthead seabream liver fatty acid profiles. The fatty acid profiles of fish consuming diets D5 and D6 formed succinct groups to the right of the plot and they were well defined by PC1. The fatty acid profiles of fish consuming diets D1-D4 were negatively correlated to PC1 and there was considerable overlap (variability) between the dietary treatments. PC2 accounted for $15.3 \%$ of the total variance and was important to distinguish individual liver fatty acid profiles of fish consuming diets D1-D3. (b) Variables (fatty acids) used to construct the principal components. The circle in this plot is the correlation circle, the stronger the correlation of a fatty acid to PC1 and, or PC2 the closer its arrowhead to the circle. Arrowheads that do not approach the circle are not well represented by PC1 and PC2 (e.g. 22:0). The arrows indicate how the fatty acids contributed to the formation of PC1 and PC2 and thus the formation of (a). Several points can be made to describe the data, the fatty acids derived from fish oil (e.g. 22:6n-3) were strongly correlated to PC1, the main fatty acids from vegetable oil (e.g. 18:1n-9) were negatively correlated to PC1. Several fatty acids were best explained by a combination of PC1 and PC2, including 18: $2 n-9$ and $20: 2 n-9$, and it can be said that these fatty acids are important to distinguish liver fatty acid profiles from fish consuming diets D1-D4. $\circ$, D1; $\triangle$, D2; $\square, \mathrm{D} 3 ;+, \mathrm{D} 4 ;$, $\mathrm{D} 5 ;$ *, $\mathrm{D} 6$

(a)

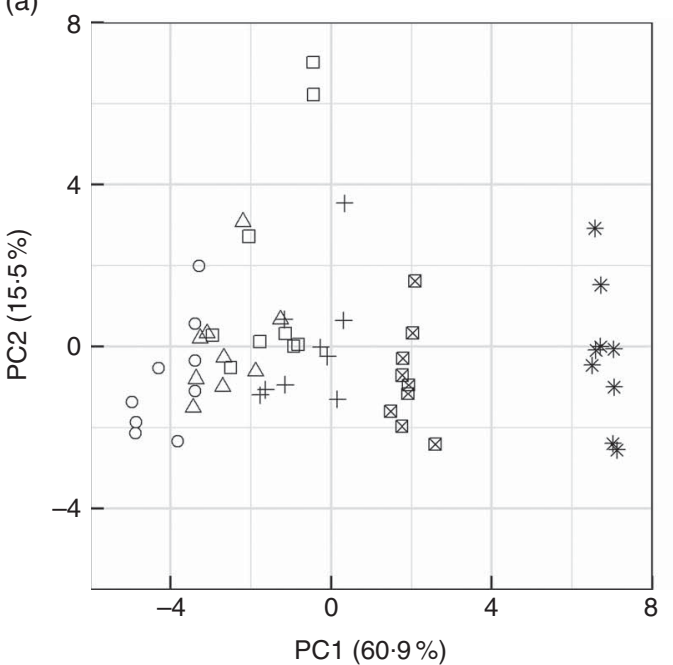

(b)

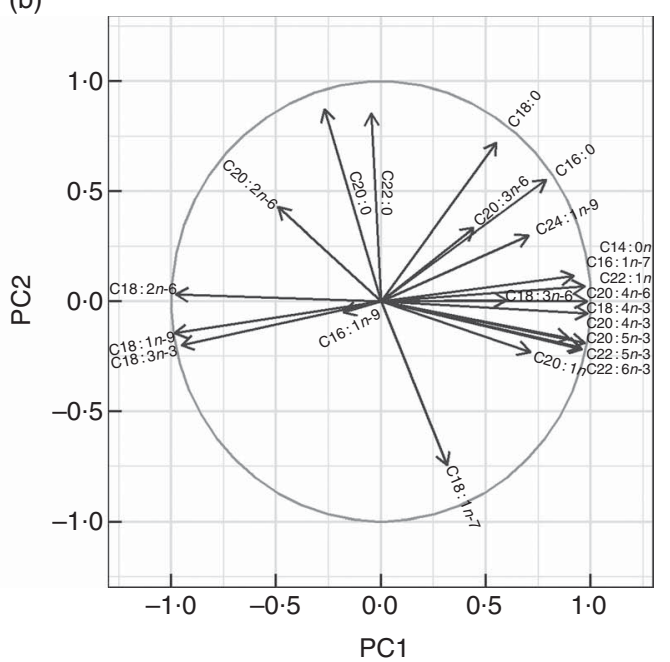

Fig. 2. Graphical representation of principal components analysis (PCA) of fatty acid profiles from mid-intestine ( $n$ 54) of fish fed experimental diets (D1-D6). The two panels are complimentary to one another. (a) Biplot of the first two principal components (PC1 and PC2) of seabream mid-intestine fatty acid profiles. The fatty acid profiles of fish consuming diets D5 and D6 formed succinct groups to the right of the plot. The fatty acid profiles of fish consuming diets D1-D3 were negatively correlated to PC1 and there was considerable overlap in the points. PC2 separated the fatty acid profiles vertically and explained $15.5 \%$ of the variance, two outliers appeared in D3 and these samples contained unusually high levels 20:0 and 22:0 and, other than these samples, the variance was quite evenly distributed amongst the diets when compared with liver. (b) Variables (fatty acids) used to construct the principal components. The circle in this plot is the correlation circle, the stronger the correlation of a fatty acid to PC1 and, or PC2 the closer its arrowhead to the circle. Arrowheads that do not approach the circle were not well represented by PC1 and PC2 (e.g. 16:1n-9). The arrows indicate how the fatty acids contributed to the formation of PC1 and PC2 and thus the formation of plot A. ○, D1; $\triangle, \mathrm{D} 2 ; \square, \mathrm{D} 3 ;+, \mathrm{D} 4 ; \otimes+\mathrm{D} 5 ;$ * , D6.

liver were typically $75-175 \mathrm{mg} / \mathrm{g}$ in fish fed diets D1-D4, and $<50 \mathrm{mg} / \mathrm{g}$ in fish consuming the FO diet (D6). High variability is evident in MUFA levels with the major contributing factor being variation in the total lipid content of the tissues. Two fatty acids, namely $18: 2 n-9$ and $20: 2 n-9$, were identified in liver in spite of their absence in diets and mid-intestine, 
(a)

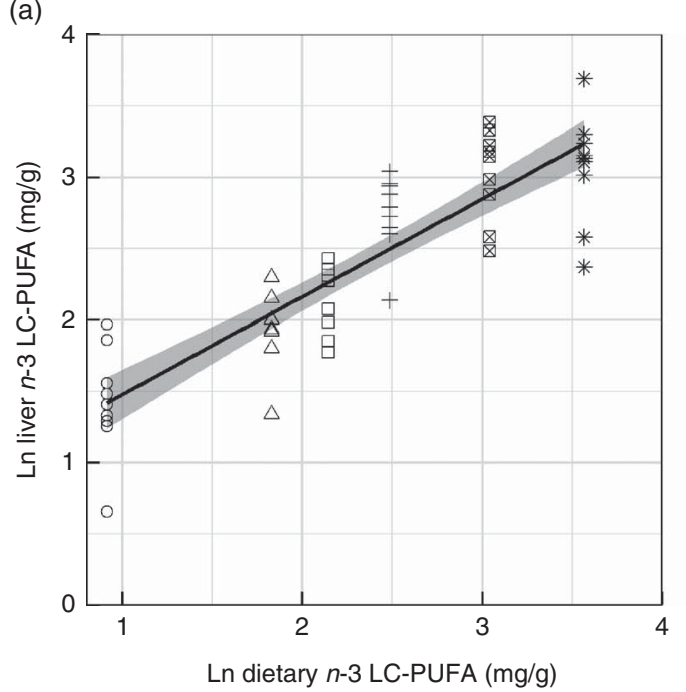

(b)

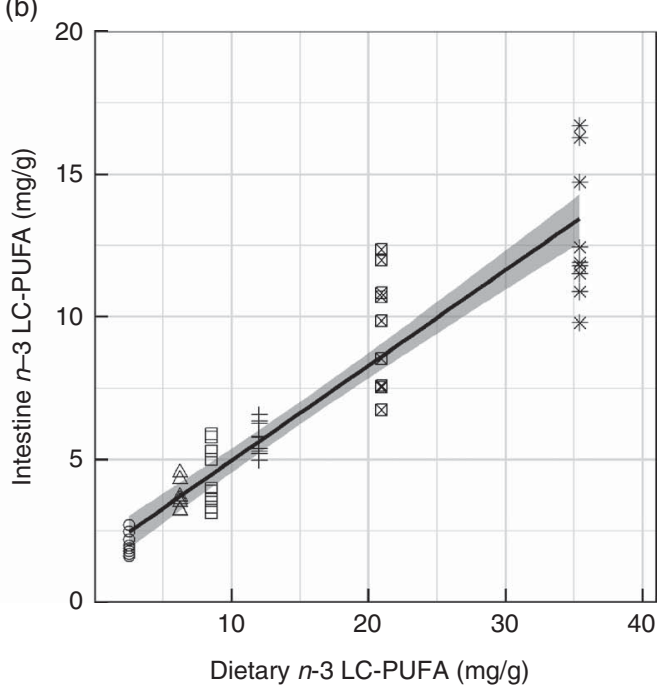

Fig. 3. Levels of $n-3$ long-chain ( $\geq C_{20}$ ) PUFA (LC-PUFA) in gilthead seabream liver (a) and mid-intestine (b) against the dietary levels of $n$-3 LC-PUFA. The natural logarithm (In) transformation applied to the data in (a) indicates that in liver this relationship was not linear. Both models were linear ordinary least squares fits with the standard error shaded in grey ( $n 54)$. ०, Diet 1; $\triangle$, Diet 2; $\square$, Diet 3; +, Diet 4; $\otimes$, Diet 5 ; *, Diet 6.

(a)

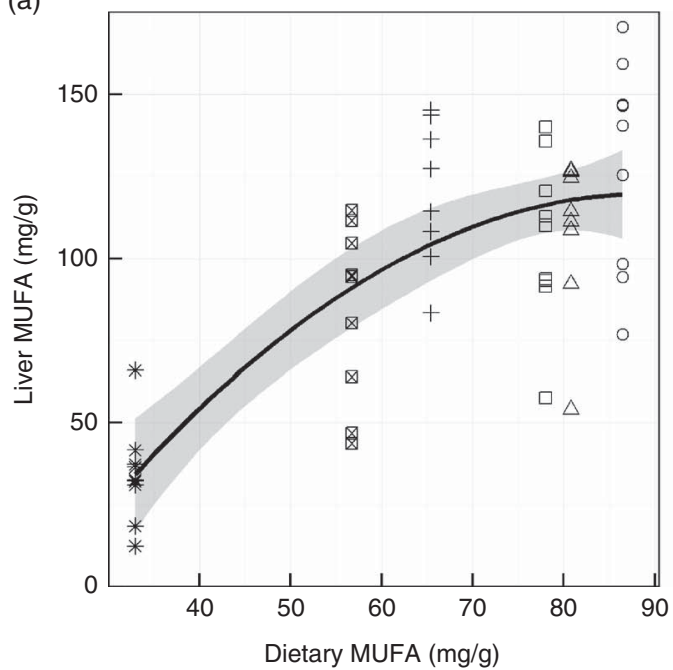

(b)

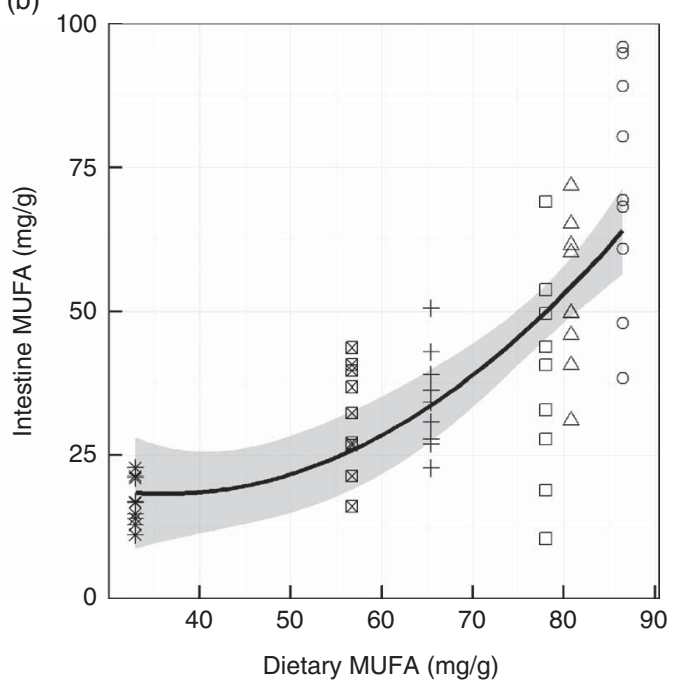

Fig. 4. Levels of MUFA in gilthead seabream liver (a) and mid-intestine (b) against the dietary levels of MUFA. Both are quadratic ordinary least squares fits with the standard error shaded in grey $(n 54)$. ॰, Diet $1 ; \triangle$, Diet $2 ; \square$, Diet $3 ;+$, Diet $4 ; \otimes$, Diet 5 ; $*$, Diet 6 .

so they were plotted against dietary VO. Levels of $18: 2 n-9$ increased with the dietary VO $\left(R^{2}=0 \cdot 81, P<0 \cdot 001\right)$ (Fig. 5(a)). The level of $18: 2 n-9$ was correlated $\left(R^{2}=0.41, r\right.$ 0.64, $P<0.001$ ) to the $\log _{2}$ expression of fads2 (Fig. 5(b)), the latter data requiring to be transformed to satisfy the assumptions of Pearson's correlation. Dietary levels of saturates were relatively stable across the experimental diets $(32-36 \mathrm{~g} / \mathrm{kg})$. Despite this low range, livers of fish fed diet D1 (VO rich) contained $50-70 \mathrm{mg} / \mathrm{g}$ saturates and those of fish fed diet D6 (FO rich) ranged between 10 and $40 \mathrm{mg} / \mathrm{g}$, and there was a significant relationship with dietary saturates $\left(R^{2}=0.27\right.$, $P<0.001$ ) (data not shown). Examination of percentage data indicated that absolute levels of saturates was mainly associated with the increasing lipid level of the liver, lower levels of saturates were observed in the mid-intestine $(15-35 \mathrm{mg} / \mathrm{g})$. Quantitatively, palmitic acid was the dominant SFA in both tissues and only 14:0 increased with dietary FO. Liver and mid-intestine fatty acid data are summarised in the online Supplementary Tables S2 and S3, respectively, where they are analysed by ANOVA, with the results being in agreement with those reported above.

\section{Gene expression}

Genes representing lipid metabolic pathways were assayed by qPCR, and the expression of target genes plotted against dietary VO and, although variability $\left(R^{2}=19-52 \%\right)$, between individuals was high, significant trends showed that the diets 
(a)

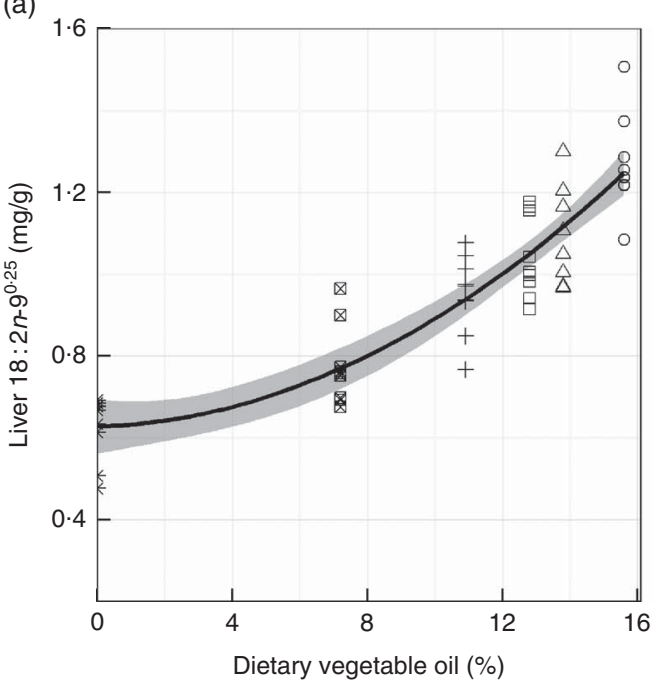

(b)

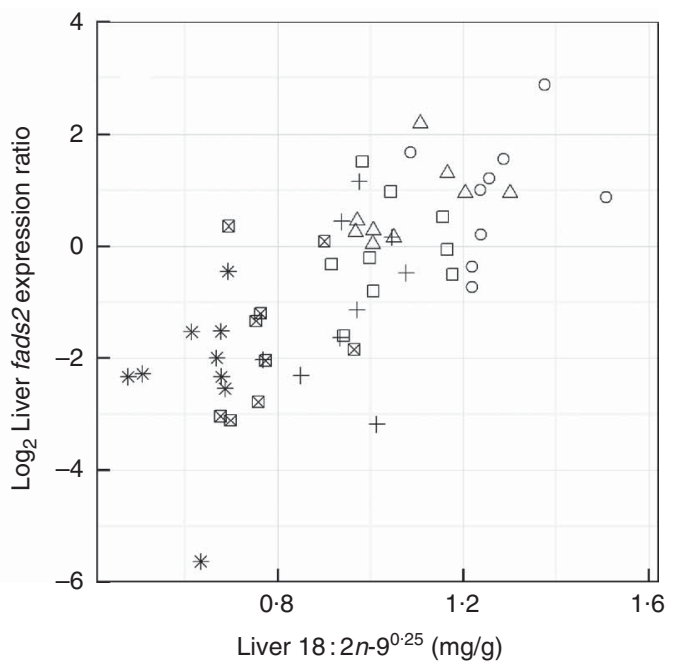

Fig. 5. Levels of $18: 2 n-9^{0.25}$, which is not present in the diets, in gilthead seabream liver against dietary vegetable oil (a), and the level of fatty acid desaturase 2 (fads2) expression correlated $(r 0.64 ; P<0.001)$ with the levels of $18: 2 n-9^{0.25}$ in liver (b). The model applied in $A$ is a quadratic ordinary least squares fit with the standard error shaded in grey $(n 54)$. The transformation $\left(x^{0.25}\right)$ is applied to the $18: 2 n-9$ data. $\circ$, Diet $1 ; \triangle$, Diet 2 ; $\square$, Diet 3 ;,+ Diet $4 ; \otimes$, Diet 5 ; *, Diet 6.

had an impact on the regulation of lipid metabolism. Subtle, negative trends were found in the liver between dietary VO and the expression of ppara $1\left(R^{2}=0.32, P<0.001\right)$ and its target genes cpt1 $\alpha \quad\left(R^{2}=0 \cdot 26, \quad P<0 \cdot 001\right)$ and fabp1 $\left(R^{2}=0 \cdot 19\right.$, $P<0.001)$ (Fig. 6). The highly variable within treatment data indicated that diet is not the sole source of this variation in the expression of these genes. The level of variation in the midintestine prevented the application of suitable models to the data. In the liver, positive trends, fitted with quadratic functions were found between VO and $\operatorname{srebp} 1\left(R^{2}=0.37, P<0.001\right)$ and its target genes fas $\left(R^{2}=0.42, P<0.001\right)$ and fads $2\left(R^{2}=0.52\right.$, $P<0.001$ ) (Fig. 7). Effects of $\mathrm{VO}$ on the expression of srebp2 and elovl5 in liver were not detected (data not shown). However, in mid-intestine, the effect on srebp1 expression was not as strong and linear $\left(R^{2}=0.23, \quad P<0.001\right)$, but srebp 2 showed a strong up-regulation in fish fed diets D1 and D2 $\left(R^{2}=0.49, \quad P<0.001\right)$ and elovl5 was responsive to dietary VO $\left(R^{2}=0 \cdot 26, P<0 \cdot 001\right)$ (Fig. 8). Effects of VO on the expression of fads 2 were not detected in mid-intestine (data not shown).

\section{Discussion}

Replacement of FO by alternative oils in aquafeeds has been an extensively investigated research topic over the last two decades $^{(16)}$. The most common FO alternatives are VOs, for example rapeseed oil or soyabean oil, which are devoid of essential LC-PUFA and, consequently, their use has important implications, not only on the nutritional value of the product for consumers $^{(36-38)}$, but also effects on metabolism and fish health $^{(1)}$. We employed a dietary gradient of VO to span the EFA requirements reported for a commercially relevant teleost, the gilthead seabream ${ }^{(26)}$ and show how this gradient modifies the composition and the expression of lipid metabolic and regulatory genes in gilthead seabream juveniles.
Fish consuming diets D4-D6 (LC-PUFA: 1.20-3.54\% of diet) gained significantly more weight than the other dietary groups, a likely result that these diets were supplied EPA and DHA in excess of the nutrient requirement. The results of the present study show that dietary provision of $n$-3 LC-PUFA below the reported EFA requirement, $0.9 \% \mathrm{EPA}+\mathrm{DHA}$ dry weight, for gilthead seabream $^{(15)}$ led to alterations in lipid metabolism as indicated by increased lipid content in liver and decreased lipid in viscera, the latter being regarded as the normal lipid storage site in this species ${ }^{(39)}$. These results were in agreement with previous studies regarding increased hepatic lipid content as a result of dietary deficiency of EPA and DHA in gilthead seabream $^{(13,17,40)}$ and other fish species ${ }^{(1,41)}$. Interestingly, increased lipid contents in liver have been also described when dietary lipid was increased to boost the energy content of the diet ${ }^{(42)}$. The range of values for hepatic total lipid was 17-32\% (wet wt) and these were higher than those reported previously, 15-25\% (wet wt), in gilthead seabream fed graded levels of soyabean oil $^{(13)}$. This may be due to the larger size of the fish in the present trial (24-230g) whereas the previous study used fry (1.2-12.4 g), the longer feeding period of 4 months in the present study, or the higher crude lipid levels in the diets. In the previous study there was a threshold level of soyabean oil (approximately $50 \%$ of oil) that increased hepatic lipid content whereas data in the present study suggested VO increased hepatic lipid in a concentration-dependant manner (linear increase).

Quantitatively, the main fatty acids driving the increased liver lipid were 18:1n-9 (oleic acid), 18:2n-6 (linoleic acid) and $18: 3 n-3$ ( $\alpha$-linolenic acid), all major constituents of the VO used in the experimental diets. Such accumulation of dietary fatty acids observed in liver, occurring as well in mid-intestine, has been commonly reported in FO replacement studies in gilthead seabream $^{(12,13,43)}$. Interestingly, two fatty acids, namely $18: 2 n-9$ and $20: 2 n-9$, were found in the liver, but not mid-intestine, of 
(a)

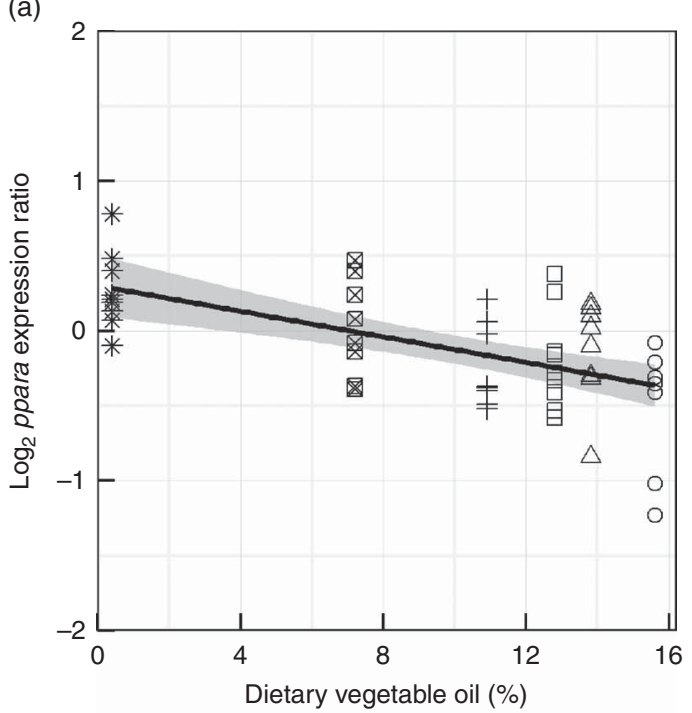

(b)

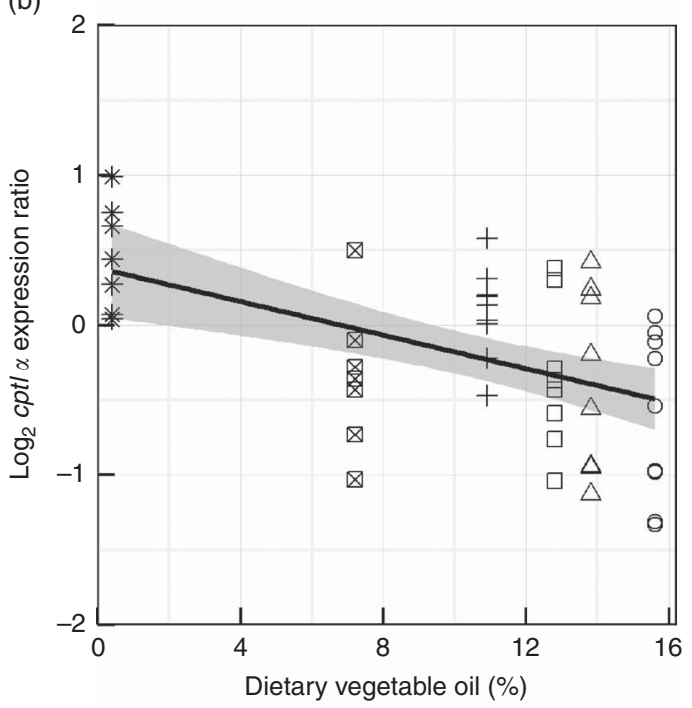

(c)

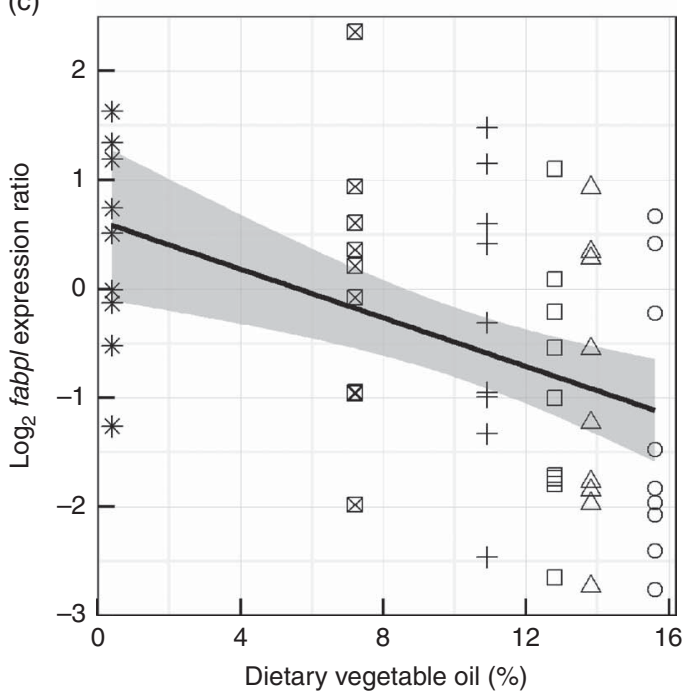

fish fed VO that were not present in the diets. The presence of $18: 2 n-9$ is likely to be the result of $\Delta 6$ desaturation of $18: 1 n-9$, with $20: 2 n-9$ being the elongation product of $18: 2 n-9$. Fads 2 is typically a $\Delta 6$ desaturase in marine teleosts ${ }^{(23)}$ and, although its activity towards $18: 1 n-9$ has not been demonstrated in gilthead seabream $^{(44)}$, it is likely that Fads2 activity was responsible for observed production of $18: 2 n-9$ in liver. Additional data in the form of enzyme protein levels or activity assays could lend support to this conclusion. Indeed, this is consistent with increased expression of fads 2 in liver of fish fed high VO diets and $n$-3 LC-PUFA deficient diets, a regulatory mechanism often reported in literature not only on desaturases, as observed herein, but also elongases such as elovl $5^{(19)}$. Interestingly, an up-regulation of hepatic elovl5 was not observed, that would support the production of $20: 2 n-9$ mentioned above. Instead, a moderate but detectable increase in elovl5 expression was observed in the mid-intestine with dietary $\mathrm{VO}$, in agreement with previous studies on seabream ${ }^{(45)}$, and it is likely that this decrease is a response to declining availability of $n-3$ LC-PUFA. Hepatic fads 2 expression was variable between individual fish fed diets with high VO inclusion (D1-D4). The PCA analysis showed that this was also the case for the fatty acid profiles of fish consuming these diets and that $18: 2 n-9$ and $20: 2 n-9$ were important fatty acids in driving this variability. Furthermore, the level of $18: 2 n-9$ was strongly correlated to the level of fads 2 transcripts in the liver. It may be possible to exploit this individual variability in response to VO to select seabream that are better adapted to diets that are rich in $\mathrm{VO}$, as has been described previously in Atlantic salmon ${ }^{(18)}$. The fatty acids, $18: 2 n-9$ and $20: 2 n-9$, are metabolites of $18: 1 n-9$ derived from its metabolism via the LC-PUFA biosynthesis pathway. Marine fish are able to perform the first two steps, $\Delta 6$ desaturation (fads2) and elovl5, but are unable to perform the subsequent step of the pathway due to the absence of an active $\Delta 5$ desaturase ${ }^{(46)}$. The above result shows that the $\Delta 6$ in seabream can operate on $18: 1 n 9$.

In addition to the distinctive patterns of fads 2 and elovl5 expression described above, the regulatory mechanisms by which dietary fatty acids modulate metabolic responses in liver and mid-intestine appear to differ. In liver, srebp1, but not srebp2, was increased in gilthead seabream fed diets D1-D3, with a threshold between diets D3 and D4, interestingly this at the point where effects on growth were also observed. In midintestine, both srebp1 and srebp2 expression were increased with dietary VO. Srebp signalling is responsible for maintaining lipid levels in balance and, although there is some overlap between the functions of Srebp1 and Srebp2, the former is mainly associated with fatty acid/lipid synthesis, whereas the latter is associated with cholesterol synthesis in mammals ${ }^{(22,47,48)}$ and fish ${ }^{(49)}$. While the up-regulation of srebp1 has

Fig. 6. Hepatic gene expression of ppara1 (a), carnitine palmitoyl transferase I $(c p t 1 a)$ (b) and fatty acid binding protein (fabp 1) (c) against dietary vegetable oil. Data are $\log _{2}$ (expression ratios) normalised to four reference genes and then to the calibrator sample. Fitted lines are linear functions with the standard error highlighted in grey $(n 54)$. $\circ$, Diet $1 ; \triangle$, Diet $2 ; \square$, Diet $3 ;+$, Diet $4 ; \bigotimes$, Diet 5 ; * Diet 6 . 
(a)
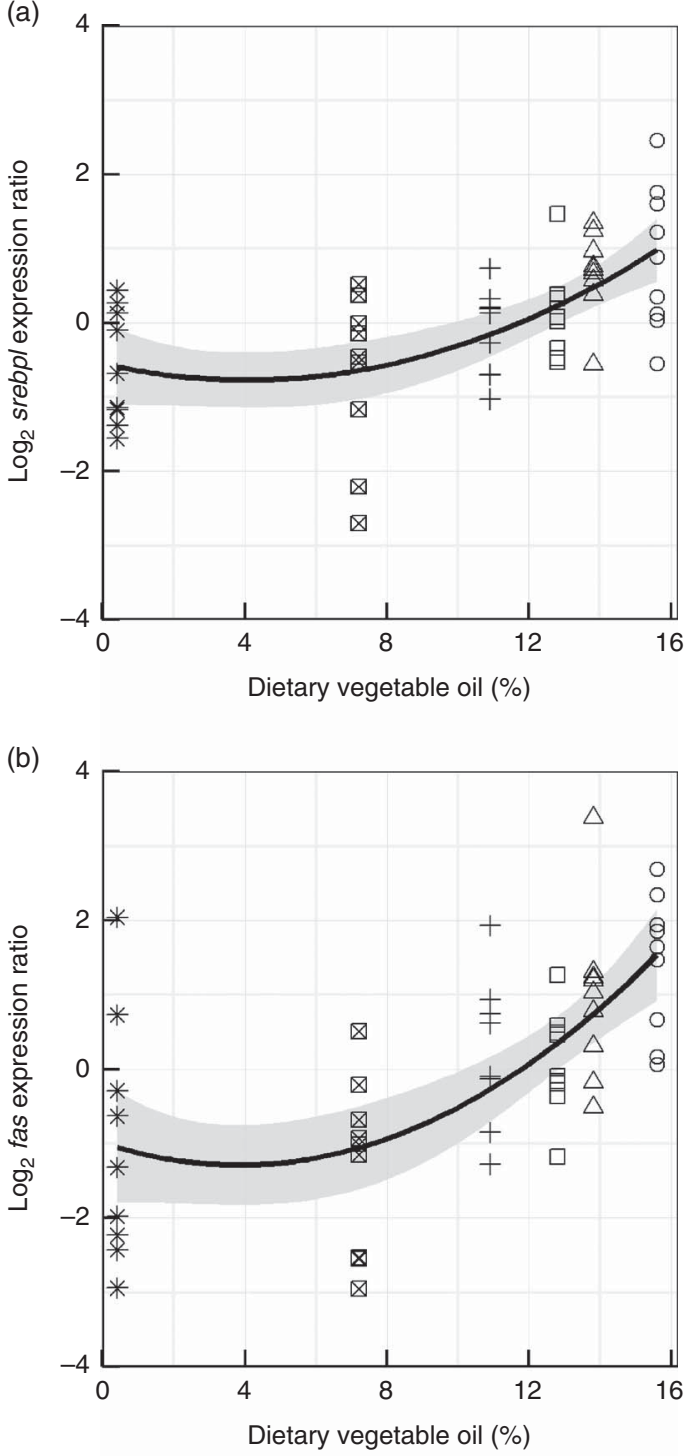

(c)

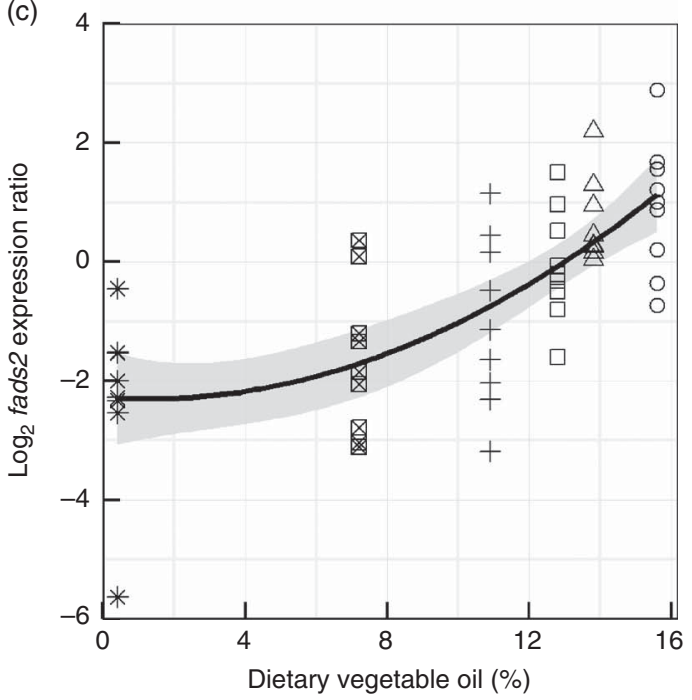

been often associated with increased expression of fads 2 in response to VO-rich diets ${ }^{(18,19,50)}$, the up-regulation of srebp2 in mid-intestine suggested putative activation of cholesterol biosynthesis. Cholesterol was added to the experimental diets to balance the supply of this key nutrient, but VO are known to contain a range of phytosterols that may have stimulated upregulation in the mid-intestine ${ }^{(25,51-53)}$.

The fas gene is also regulated by Srebp $1^{(22)}$ and its product, Fas, is an enzyme complex responsible for de novo synthesis of $\mathrm{SFA}^{(54,55)}$. Despite the inclusion of $20 \%$ lipid in the diets, the inclusion of VO resulted in up-regulation of fas in liver. There have been reports of $\mathrm{VO}$ increasing fas expression in Atlantic salmon $^{(18)}$ and black seabream ${ }^{(19)}$. Nevertheless, this is not always supported by measurements of Fas activity in gilthead seabream fed diets with $80 \%$ of dietary FO replaced with linseed oil ${ }^{(20)}$ however, in turbot (Scophthalmus maximus), Fas activity was stimulated by dietary $\mathrm{VO}$ although the differences were $\mathrm{NS}^{(56)}$. It is unclear what exactly is responsible for the apparent discrepancy between these results. However, the increased expression of srebp1 in response to dietary VO, particularly notable in liver, suggested increased regulatory activity of Srebp1 towards potential target genes including fas and thus increasing their transcription. The patterns of dietary regulation of srebp1 and fas share a similar shape in liver (modelled by quadratic functions) suggesting co-regulation. Their up-regulation in response to dietary VO indicated that de novo lipogenesis may contribute to increased lipid deposition, as suggested previously by Morais et al. ${ }^{(18)}$ when studying diet/ genotype interactions in Atlantic salmon.

Beyond the anabolic processes described above, the impact of dietary VO was further evidenced in lipid catabolic processes such as $\beta$-oxidation. Generally, the expression of catabolic genes (ppar 1 and $c p t 1 \alpha$ ) in liver and, to some extent, in midintestine, decreased with increasing dietary $\mathrm{VO}$ mid-intestine. The data were variable as illustrated by low $R^{2}$ values, indicating that the diet was not the sole source of variation in the expression of these genes. The reduction in catabolic gene expression is coherent with the observed increased hepatic lipid levels associated with dietary VO. Furthermore, the results were consistent with previous studies in rats ${ }^{(57,58)}$ and Atlantic salmon ${ }^{(18)}$ that revealed that dietary FO increased the expression of ppar $\alpha$ and the activity of $\beta$-oxidation enzymes. In contrast, a recent study demonstrated expression of ppar 1 and its target $c p t 1 \alpha$ were increased in liver of gilthead seabream fed diet containing both wild-type Camelina sativa oil (a low LC-PUFA diet) and containing GM camelina oil (containing $n-3$ LC-PUFA), although both these diets contained sufficient FM to satisfy EFA requirements ${ }^{(59)}$. Dong et $a l{ }^{(60)}$ have recently shown that ppar 1 expression in response to VO was different in three species of fish. The authors observed, dietary VO

Fig. 7. Hepatic gene expression of sterol regulatory element-binding protein 1 (srebp1) (a), fatty acid synthase (fas) (b) and fatty acid desaturase 2 (fads2) (c) against dietary vegetable oil. Data are $\log _{2}$ (expression ratio) normalised to four reference genes and then to the calibrator sample. Fitted lines are second order quadratic functions with the standard error highlighted in grey ( $n$ 54). The similarity between the responses is striking. $\circ$, Diet $1 ; \triangle$, Diet $2 ; \square$, Diet 3; + , Diet 4; $\otimes$, Diet 5; * Diet 6 . 

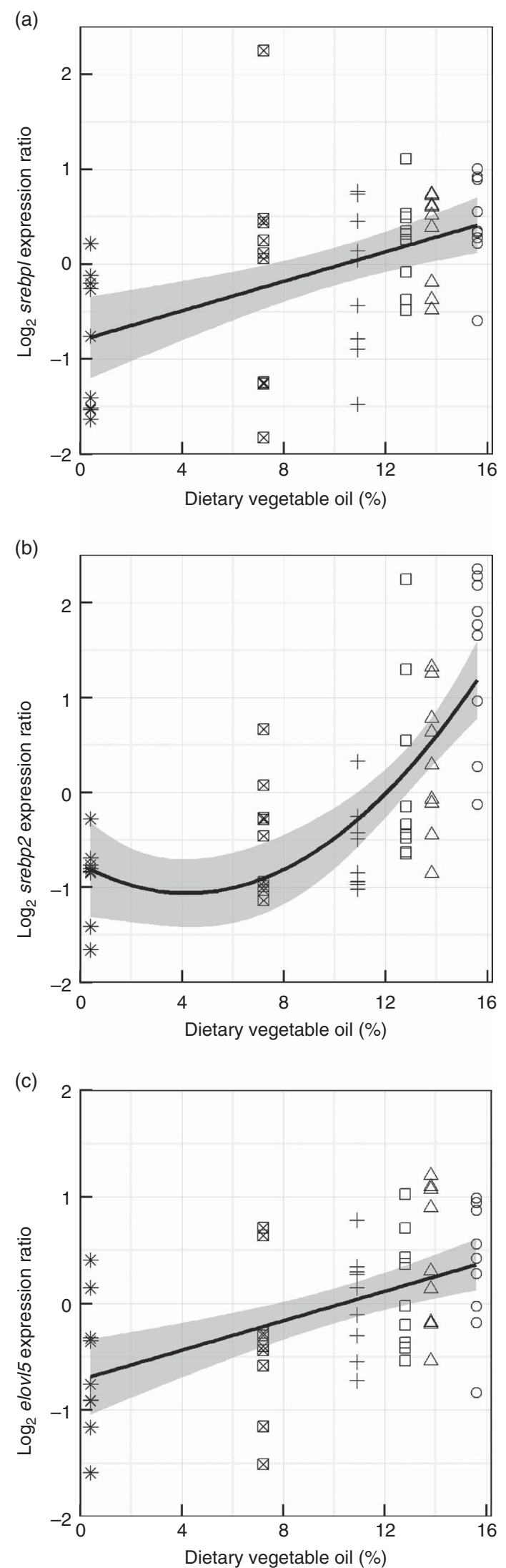

increased expression of ppara1 and ppara 2 in rainbow trout (Oncorbynchus mykiss) and decreased expression of ppara 2 in Japanese seabass (Lateolabrax japonicus), but had no effect in livers of yellow croaker (Larimichthys crocea). This finding complicates the regulation of lipid homoeostasis but means that lipid catabolic processes can be regulated by a broad range of endogenous stimuli.

In conclusion, the present study demonstrated that diets deficient in essential LC-PUFA can cause reduction in growth rates alterations to lipid metabolism, fatty acid composition of liver and the regulation of genes involved in lipogenesis and catabolism. Despite the high variability in the expression of lipogenic genes the effect of their expression appears to be become measurable in D1-D3 and this agrees with the analysis of the final weight and SGR data. Therefore, the alteration to the expression of the genes involved in lipogenesis and energy balance appear to be related to the fish growth performance. Therefore, D4-D6 appear to provide sufficient EFA and D1-D3 appear to be deficient. Despite the high energy (high lipid) diets used in the present study, expression of lipogenic genes such as fas involved in de novo biosynthesis was increased by dietary VO. In contrast, ppara1 and its target $\operatorname{cpt} 1 \alpha$ were downregulated and the expression was linear and therefore appeared to be modulated in a concentration-dependant manner. However, the expression of srebp1 and its gene targets was modelled by a curve, which was indicative of a threshold concentration at which gene expression was activated, although it is difficult to determine this point due to high variability between fish. Overall, the results reported in the present study were consistent with those reported in rats ${ }^{(61)}$, that the LC-PUFA found in FO have a stimulating effect on $\beta$-oxidation and an inhibitory effect on de novo lipogenesis. These opposing biochemical activities would be expected to contribute towards the increased hepatic lipid observed in fish fed increasing VO in the present study and others investigating EFA nutrition. These physiological effects of $\mathrm{VO}$ have direct relevance to decisions regarding sustainable and modern feed formulations for marine fish species.

\section{Acknowledgements}

The authors express their gratitude to the technical team at the BioMar Feed Trial Unit, Hirtshals, in particular, Svend Jørgen Steenfeldt for expert care of the experimental subjects, for training and supervision provided by laboratory staff at Nutrition Analytical Services and Molecular Biology at the Institute of Aquaculture, University of Stirling, UK.

S. J. S. H's. PhD was co-funded by BioMar and the Marine Alliance for Science and Technology Scotland. BioMar provided

Fig. 8. Mid-intestine gene expression of sterol regulatory elementbinding protein 1 (srebp1) (a), srebp2 (b) and elongation of very long-chain fatty acid 5 protein (elovl5) (c) against dietary vegetable oil. Data are $\log _{2}$ (expression ratio) normalised to four reference genes and then to the calibrator sample. Fitted lines are linear fits for srebp1 and elovl5 and a second order quadratic function is fitted to srebp2. The model standard errors are highlighted in grey $(n 54)$. ०, Diet $1 ; \triangle$, Diet $2 ; \square$, Diet $3 ;+$, Diet 4 ; $\bigotimes$, Diet 5; * Diet 6. 
the experimental feeds, trial facilities and fish, and covered travel expenses

V. K. and J. T. designed and executed the nutritional trial and all authors contributed to planning the analyses. V. K., J. T. and S. J. S. H. carried out the sampling. O. M., D. R. T and S. A. M. M. supervised the lead author. M. B. B. provided training in molecular biology to S. J. S. H. who carried out all analytical procedures. S. J. S. H. analysed all of the data and prepared the manuscript. Subsequently the manuscript was shared between all authors who made amendments, contributions and recommendations.

The authors declare that there are no conflicts of interest.

\section{Supplementary material}

For supplementary material/s referred to in this article, please visit https://doi.org/10.1017/S0007114517002975

\section{References}

1. Glencross BD (2009) Exploring the nutritional demand for essential fatty acids by aquaculture species. Rev Aquacult 1, 71-124.

2. Pike IH \& Jackson A (2010) Fish oil: production and use now and in the future. Lipid Technol 22, 59-61.

3. Merino G, Barange M, Blanchard JL, et al. (2012) Can marine fisheries and aquaculture meet fish demand from a growing human population in a changing climate? Global Environ Change 22, 795-806.

4. Tacon AGJ \& Metian M (2015) Feed matters: satisfying the feed demand of aquaculture. Rev Fish Sci Aquacult 23, $1-10$.

5. Tocher DR (2015) Omega-3 long-chain polyunsaturated fatty acids and aquaculture in perspective. Aquaculture $\mathbf{4 4 9}$, 94-107.

6. Gawrisch K, Eldho NV \& Holte LL (2003) The structure of DHA in phospholipid membranes. Lipids 38, 445-452.

7. Serhan CN, Chiang N \& Van Dyke TE (2008) Resolving inflammation: dual anti-inflammatory and pro-resolution lipid mediators. Nat Rev Immunol 8, 349-361.

8. Oliva-Teles A (2012) Nutrition and health of aquaculture fish. J Fish Dis 35, 83-108.

9. Tocher DR (2003) Metabolism and functions of lipids and fatty acids in teleost fish. Rev Fish Sci 11, 107-184.

10. Jordal AO, Torstensen BE, Tsoi S, et al. (2005) Dietary rapeseed oil affects the expression of genes involved in hepatic lipid metabolism in Atlantic salmon (Salmo salar L.). J Nutr 135, 2355-2361.

11. Izquierdo MS, Montero D, Robaina L, et al. (2005) Alterations in fillet fatty acid profile and flesh quality in gilthead seabream (Sparus aurata) fed vegetable oils for a long term period. Recovery of fatty acid profiles by fish oil feeding. Aquaculture 250, 431-444.

12. Benedito-Palos L, Navarro JC, Sitjà-Bobadilla A, et al. (2008) High levels of vegetable oils in plant protein-rich diets fed to gilthead sea bream (Sparus aurata L.): growth performance, muscle fatty acid profiles and histological alterations of target tissues. Br J Nutr 100, 992-1003.

13. Kalogeropoulos N, Alexis MN \& Henderson RJ (1992) Effects of dietary soybean and cod-liver oil levels on growth and body composition of gilthead bream (Sparus aurata). Aquaculture 104, 293-308.
14. Sargent JR, Tocher DR \& Bell JG (2002) The lipids. In Fish Nutrition, pp. 181-257 [JE Halver and RW Hardy, editors]. San Diego, CA: Elsevier Press.

15. National Research Council, editor (2011) Nutrient Requirements of Fish and Shrimp. Washington, DC: The National Academies Press.

16. Turchini GM, Ng W \& Tocher DR (2010) Fish Oil Replacement and Alternative Lipid Sources in Aquaculture Feeds. Boca Raton, FL: CRC Press

17. Caballero MJ, Izquierdo MS, Kjørsvik E, et al. (2004) Histological alterations in the liver of sea bream, Sparus aurata L., caused by short- or long-term feeding with vegetable oils. Recovery of normal morphology after feeding fish oil as the sole lipid source. J Fish Dis 27, 531-541.

18. Morais S, Pratoomyot J, Taggart JB, et al. (2011) Genotypespecific responses in Atlantic salmon (Salmo salar) subject to dietary fish oil replacement by vegetable oil: a liver transcriptomic analysis. BMC Genomics 12, 1.

19. Jin M, Lu Y, Yuan Y, et al. (2017) Regulation of growth, antioxidant capacity, fatty acid profiles, hematological characteristics and expression of lipid related genes by different dietary $n-3$ highly unsaturated fatty acids in juvenile black seabream (Acanthopagrus schlegelii). Aquaculture 471, 55-65.

20. Menoyo D, Izquierdo MS, Robaina L, et al. (2004) Adaptation of lipid metabolism, tissue composition and flesh quality in gilthead sea bream (Sparus aurata) to the replacement of dietary fish oil by linseed and soyabean oils. BrJ Nutr 92, 41-52.

21. Takeuchi Y, Yahagi N, Izumida Y, et al. (2010) Polyunsaturated fatty acids selectively suppress sterol regulatory element-binding protein-1 through proteolytic processing and autoloop regulatory circuit. J Biol Chem 285, 11681-11691.

22. Daemen S, Kutmon M \& Evelo CT (2013) A pathway approach to investigate the function and regulation of SREBPs. Genes Nutr 8, 289.

23. Castro C, Corraze G, Basto A, et al. (2016) Dietary lipid and carbohydrate interactions: implications on lipid and glucose absorption, transport in gilthead sea bream (Sparus aurata) juveniles. Lipids 51, 743-755.

24. Mandard S, Müller M \& Kersten S (2004) Peroxisome proliferator-activated receptor $\alpha$ target genes. Cell Mol Life Sci 61, 393-416

25. Leaver MJ, Villeneuve LA, Obach A, et al. (2008) Functional genomics reveals increases in cholesterol biosynthetic genes and highly unsaturated fatty acid biosynthesis after dietary substitution of fish oil with vegetable oils in Atlantic salmon (Salmo salar). BMC Genomics 9, 299-2164-9-299.

26. Teles AO, Lupatsch I \& Nengas I (2011) Nutrition and feeding of sparidae. In Sparidae, pp. 199-232 [MA Pavlidis and CC Mylonas, editors]. Oxford: Wiley-Blackwell.

27. Horwitz W (2000) Official Methods of Analysis of the AOAC International. Gaithersburg, MD: AOAC International

28. Folch J, Lees M \& Sloane Stanley GH (1957) A simple method for the isolation and purification of total lipides from animal tissues. J Biochem 226, 497-509.

29. Christie WW editor (2003) Lipid Analysis, Isolation, Separation, Identification and Structural Analysis of Lipids, 3rd ed. Bridgwater: The Oily Press.

30. Tocher DR \& Harvie DG (1988) Fatty acid compositions of the major phosphoglycerides from fish neural tissues; $(n-3)$ and ( $n$-6) polyunsaturated fatty acids in rainbow trout (Salmo gairdneri) and cod (Gadus morhua) brains and retinas. Fish Physiol Biochem 5, 229-239.

31. Pfaffl MW (2001) A new mathematical model for relative quantification in real-time RT-PCR. Nucleic Acids Res 29, e45.

32. Hellemans J \& Vandesompelle J (2011) Quantitative PCR data analysis - unlocking the secret to successful results. In $P C R$ 
Trouble Shooting and Optimization: The Essential Guide, pp. 139-150 [S Kennady and N Oswald, editors]. Caister, Norfolk: Caister Academic Press.

33. R Core Team (2015) R: A Language and Environment for Statistical Computing. Vienna: R Core Team. http://www. R-project.org/

34. Husson F, Josse J, Le S, et al. (2016) Package 'FactoMineR'. https://cran.r-project.org/web/packages/FactoMineR/Facto MineR.pdf.

35. Fox J, Weisberg S, Adler D, et al. (2017) Package 'car'. https:// cran.r-project.org/web/packages/car/car.pdf.

36. Henriques J, Dick JR, Tocher DR, et al. (2014) Nutritional quality of salmon products available from major retailers in the UK: content and composition of $n$-3 long-chain PUFA. $\mathrm{BrJ}$ Nutr 112, 964-975.

37. Sprague M, Dick JR \& Tocher DR (2016) Impact of sustainable feeds on omega-3 long-chain fatty acid levels in farmed Atlantic salmon, 2006-2015. Sci Rep 6, 21892.

38. Shepherd CJ, Monroig O \& Tocher DR (2017) Future availability of raw materials for salmon feeds and supply chain implications: the case of Scottish farmed salmon. Aquaculture 467, 49-62.

39. McClelland G, Weber J, Zwingelstein G, et al. (1995) Lipid composition off tissue and plasma in two Mediterranean fishes, the gilt-head sea bream (Chrysophyrys auratus) and the European seabass (Dicentratchus labrx). Can J Fish Aquat Sci 52, 161-170.

40. Ibeas C, Cejas J, Gómez T, et al. (1996) Influence of dietary $n-3$ highly unsaturated fatty acids levels on juvenile gilthead seabream (Sparus aurata) growth and tissue fatty acid composition. Aquaculture 142, 221-235.

41. Tocher DR, Bell JG, MacGlaughlin P, et al. (2001) Hepatocyte fatty acid desaturation and polyunsaturated fatty acid composition of liver in salmonids: effects of dietary vegetable oil. Comp Biochem Physiol B Biochem Mol Biol 130, 257-270.

42. Vergara JM, López-Calero G, Robaina L, et al. (1999) Growth, feed utilization and body lipid content of gilthead seabream (Sparus aurata) fed increasing lipid levels and fish meals of different quality. Aquaculture 179, 35-44.

43. Montero D, Robaina L, Socorro J, et al. (2001) Alteration of liver and muscle fatty acid composition in gilthead seabream (Sparus aurata) juveniles held at high stocking density and fed an essential fatty acid deficient diet. Fish Physiol Biochem 24, 63-72.

44. Zheng X, Seiliez I, Hastings N, et al. (2004) Characterization and comparison of fatty acyl $\Delta 6$ desaturase cDNAs from freshwater and marine teleost fish species. Comp Biochem Physiol B Biochem Mol Biol 139, 269-279.

45. Castro LFC, Tocher DR \& Monroig O (2016) Long-chain polyunsaturated fatty acid biosynthesis in chordates: Insights into the evolution of Fads and Elovl gene repertoire. Prog Lipid Res 62, 25-40.

46. Castro LF, Monroig O, Leaver MJ, et al. (2012) Functional desaturase Fads1 (Delta5) and Fads2 (Delta6) orthologues evolved before the origin of jawed vertebrates. PLOS ONE 7, e31950.
47. Pai J, Guryev O, Brown MS, et al. (1998) Differential stimulation of cholesterol and unsaturated fatty acid biosynthesis in cells expressing individual nuclear sterol regulatory elementbinding proteins. J Biol Chem 273, 26138-26148.

48. Amemiya-Kudo M, Shimano H, Hasty AH, et al. (2002) Transcriptional activities of nuclear SREBP-1a, $-1 \mathrm{c}$, and -2 to different target promoters of lipogenic and cholesterogenic genes. J Lipid Res 43, 1220-1235.

49. Carmona-Antoñanzas G, Tocher DR, Martinez-Rubio L, et al. (2014) Conservation of lipid metabolic gene transcriptional regulatory networks in fish and mammals. Gene 534, 1-9.

50. Glencross BD, De Santis C, Bicskei B, et al. (2015) A comparative analysis of the response of the hepatic transcriptome to dietary docosahexaenoic acid in Atlantic salmon (Salmo salar) post-smolts. BMC Genomics 16, 684 .

51. Morais S, Pratoomyot J, Torstensen BE, et al. (2011) Diet $\times$ genotype interactions in hepatic cholesterol and lipoprotein metabolism in Atlantic salmon (Salmo salar) in response to replacement of dietary fish oil with vegetable oil. Br J Nutr 106, 1457-1469.

52. Sanden M, Liland NS, Sæle $\varnothing$, et al. (2016) Minor lipid metabolic perturbations in the liver of Atlantic salmon (Salmo salar L.) caused by suboptimal dietary content of nutrients from fish oil. Fish Physiol Biochem 42, 1463-1480.

53. Tocher DR, Bendiksen EÅ, Campbell PJ, et al. (2008) The role of phospholipids in nutrition and metabolism of teleost fish. Aquaculture 280, 21-34.

54. Smith S (1994) The animal fatty acid synthase: one gene, one polypeptide, seven enzymes. FASEB J 8, 1248-1259.

55. Chirala S \& Wakil S (2004) Structure and function of animal fatty acid synthase. Lipids 39, 1045-1053.

56. Regost C, Arzel J, Robin J, et al. (2003) Total replacement of fish oil by soybean or linseed oil with a return to fish oil in turbot (Psetta maxima): 1. Growth performance, flesh fatty acid profile, and lipid metabolism. Aquaculture 217, 465-482.

57. Harris WS \& Bulchandani D (2006) Why do omega-3 fatty acids lower serum triglycerides? Curr Opin Lipidol 17, 387-393.

58. Shearer GC, Savinova OV \& Harris WS (2012) Fish oil - how does it reduce plasma triglycerides? Biochim Biophys Acta 1821, 843-851.

59. Betancor M, Sprague M, Montero D, et al. (2016) Replacement of marine fish oil with de novo omega-3 oils from transgenic camelina sativa in feeds for gilthead sea bream (Sparus aurata L.). Lipids 51, 1171-1191.

60. Dong X, Tan P, Cai Z, et al. (2017) Regulation of FADS2 transcription by SREBP-1 and PPAR- $\alpha$ influences LC-PUFA biosynthesis in fish. Sci Rep 7, 40024.

61. Ide T (2000) Effect of dietary $\alpha$-linolenic acid on the activity and gene expression of hepatic fatty acid oxidation enzymes. Biofactors 13, 9-14. 